\title{
The improvement of the surface hardness of stainless steel and aluminium alloy by ultrasonic cavitation peening
}

\author{
Styková Janka ${ }^{1}$, Müller Miloš ${ }^{1, *}$, and Hujer Jan ${ }^{1}$ \\ ${ }^{1}$ Technical University of Liberec, Faculty of Mechanical Engineering, Studentská 2, 46117 Liberec 1, Czech Republic
}

\begin{abstract}
This article presents first results of the experimental investigation of the influence of the cavitation shot less peening process on the properties of stainless steel and aluminium alloy specimens. The cavitation field was generated by an ultrasonic horn submerged in water and operated by an ultrasonic generator. The temperature of the water was controlled by thermometer and adjusted by separate water cooling system. The mass loss, the mass loss rate and the modification of the surface hardness are evaluated for different cavitation exposure intervals. The mass loss was measured by micro weighing scale and the surface hardness by the micro-hardness meter. The presented results indicates the significant improvement in the surface hardness for both tested materials.
\end{abstract}

\section{Introduction}

In liquid systems the term cavitation usually refers to the formation and collapse of cavities in the free liquid or in the proximity of submerged surfaces. Due to undesirable effects connected to the cavitation erosion the term cavitation is mainly connected to the field of the hydraulic machinery [1]. However the cavitation phenomena can also be used in many industrial applications. One of these applications is the cavitation shotless peening. The cavitation shotless peening is a method used to improve the fatigue strength and to introduce compressive residual stresses to the metallic materials.

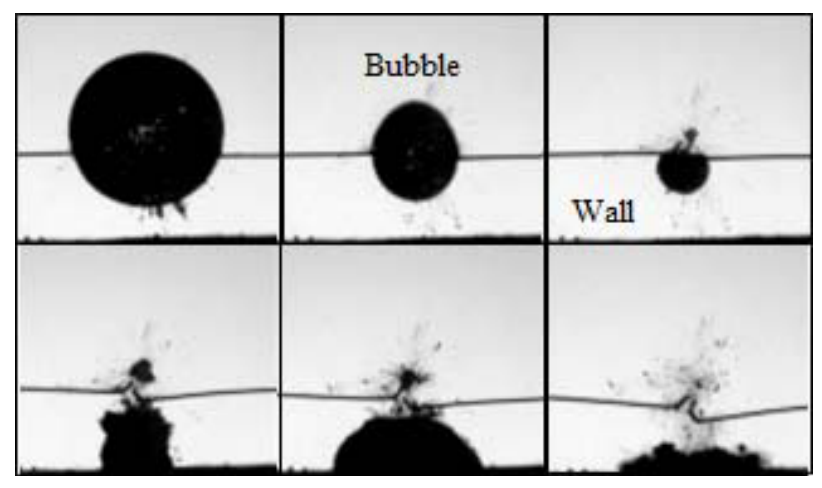

Fig. 1. Cavitation bubble collapse close to a solid surface.

The method is named "shotless peening", as no shots are required and the cavitation bubbles collapses are used instead of shooting particles [2], [3]. For instance, during the micro shot peening the particles of size 0.03 to $0.5 \mathrm{~mm}$ made of high speed tool steel, cemented carbide or ceramics are bombarding the treated surface [6] causing plastic deformation of the material.
The plastic deformation induces compressive stresses in the peened surface and tensile stresses within the material interior. The mechanical effects responsible for the cavitation erosion are produced mainly during the cavitation bubble collapse.

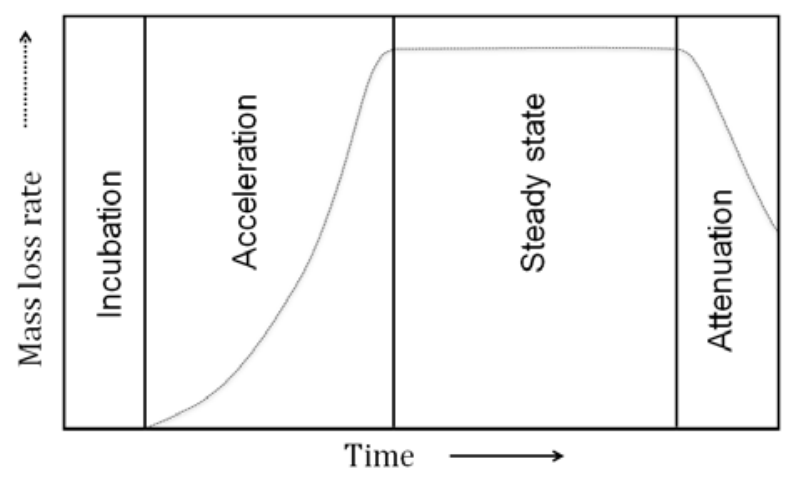

Fig. 2. Characteristic curves of the mass loss rate during the cavitation erosion.

Cavitation bubble produces during the collapse close to a solid surface a high speed liquid jet and a high pressure shock wave against the surface [1], [7]. Both these effects act as the mechanical micro hammers on treated surfaces and cause the plastic deformation similarly to the micro shot peening. The typical consequence of the cavitation bubble collapse is shown in Figure 1. Current methods used for the cavitation shot peening are classified according to the way how the cavitation is generated. One method uses cavitating jet, which is produced by the injection of a high speed water jet into the water [2]. Second method uses an ultrasonic generator to produce an ultrasonic cavitation field close

* Corresponding author: milos.muller@tul.cz 
to the specimen surface [3]. It was shown, that in the comparison with the classical shot peening methods the cavitation shot less peening exhibits considerably higher improvement in the fatigue strength [4]. The cavitation shot less peening also introduces the compressive residual stresses without considerable inverse in the surface roughness unlike the shot less peening [5]. This effect is caused by the smoother profile of pits produced by collapsing bubble unlike the sharp pit profile caused by the impacting particles.

The time evaluation of the cavitation erosion rate is shown in Figure 2. The cavitation erosion process can be divided into four periods [7]. In the incubation period no measurable mass loss is indicated. It this period, plastic deformations can occur in the impacted region and the surface roughness increases. In the acceleration period, the erosion rate increases to its maximum level. The mass loss of the material can be detected in this period. In the steady state period, the cavitation erosion rate is almost constant. In the attenuation period the erosion rate decreases. This is caused by the decrease in the cavitation collapses pressure in the vicinity of the rough surface.

It can be seen that any processes for the improvement of the material characteristic using the cavitation shot less peening should by realized during the incubation period, where no mass loss takes place. The duration of the incubation period differs based on the material properties and the preceding surface treatment.

\section{Experiment and measurement}

\subsection{Tested specimens}

For the measurement two materials stainless steel 1.4301 EN 10088-3 and aluminium alloy EN AW-2030 T3 were selected. Basic mechanical properties of selected materials are given in Table 1 . The specimen geometry is shown in Figure 3.
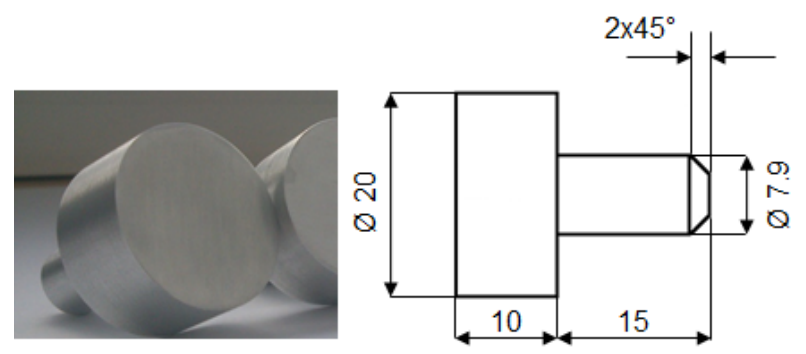

Fig. 3. Specimen geometry.

Each specimen was finished to reach the surface roughness lower than $0.8 \mu \mathrm{m}$. Number of specimens for aluminium alloy was 8 and number of specimens for stainless steel was 9. The fixation of the specimens was provided to eliminate a possible mass loss during the specimen replacement.

\subsection{Experimental setup}

The scheme of the experimental setup used for the measurement is shown in Figure 4. For the generation of the ultrasonic field of frequency $20 \mathrm{kHz} \pm 1 \mathrm{kHz}$, the ultrasonic generator UIP1000hd (Hielscher) was used. The amplitude of the horn vibrations was set for each measurement to value of $150 \mu \mathrm{m}$.

Table 1. Mechanical properties of tested materials.

\begin{tabular}{|c|c|c|c|}
\hline Material & $\begin{array}{c}\text { Minimum } \\
\text { Yield } \\
\text { Strength } \\
{[\mathrm{MPa}]}\end{array}$ & $\begin{array}{c}\text { Ultimate } \\
\text { Tensile } \\
\text { Strength } \\
{[\mathrm{MPa}]}\end{array}$ & $\begin{array}{c}\text { Ductility } \\
{[\%]}\end{array}$ \\
\hline EN 10088-3 & 350 & $700-850$ & 20 \\
\hline EN AW-2030 T3 & 250 & 400 & 10 \\
\hline
\end{tabular}

The specimen was placed $20 \mathrm{~mm}$ under the free liquid level. The working distance between the horn tip and the exposed specimen surface was set to $0.5 \mathrm{~mm}$.

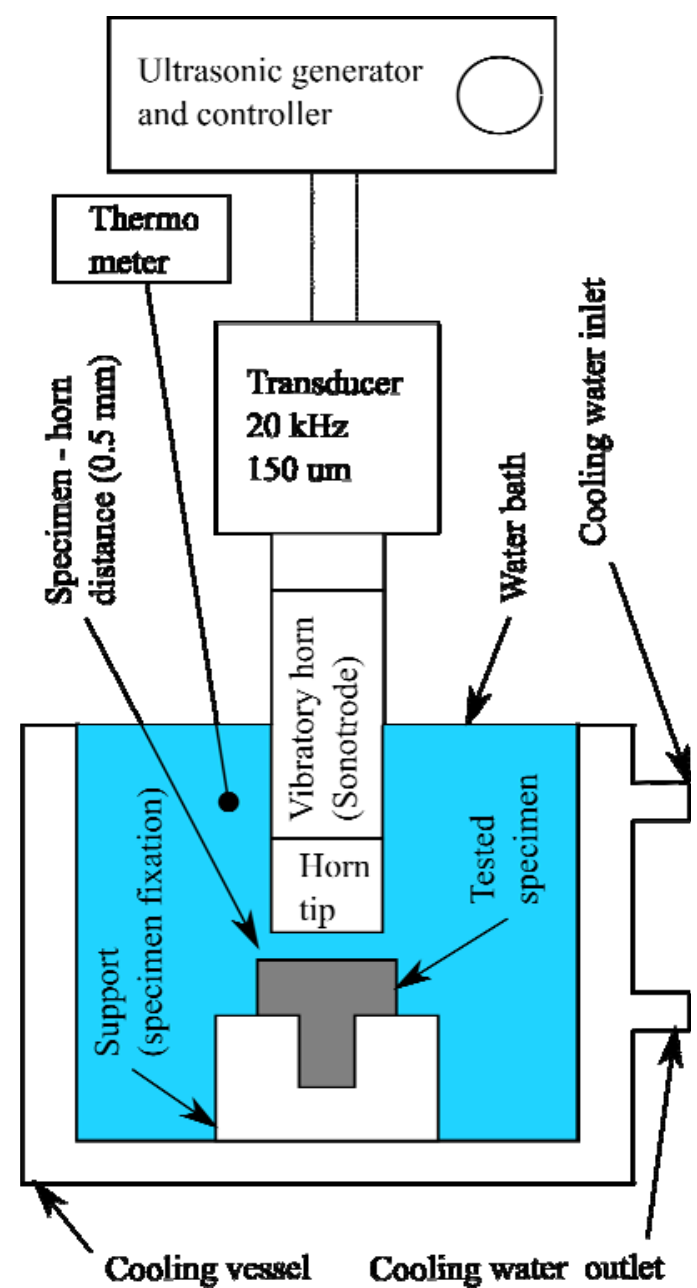

Fig. 4. Experimental setup.

Due to the intensive heat production during the testing process, water cooling system was used to stabilize the water temperature. The cooling water was introduced directly into the channels build in the vessel wall. The 
water temperature was controlled by temperature detector. Tap water of temperature $14^{\circ} \mathrm{C}$ was used for the cooling. The flow rate of the cooling liquid was set by test to reach the water temperature in range $20 \pm 2^{\circ} \mathrm{C}$. The mass of specimens was measured by micro weighing scale (Kern). The surface hardness measurement was realized by the test according to Vickers using hardness meter Zwick 3212.

\subsection{Measurement}

Each specimen for the measurement was exposed by cavitation field for a different time period. Then the mass loss and the change in the surface hardness after the exposure period were evaluated. The key problem was to set the time periods for the specimen exposure as the increase in the surface hardness is connected only to the incubation phase. Based on measurements realised by $\mathrm{Li}$ [8], the exposure time for the incubation period of stainless steel was estimated to be 75 minutes. The first specimen was exposed by the cavitation field for 45 minutes and for each other specimen the time period was extended by 15 minutes against the previous specimen period. The exposure time for aluminium alloy was set shorter due to lower mechanical properties. The specimens were exposed for 2, 3, 4, 5, 6, 10 and 15 minutes. For the mass loss evaluation each specimen was weighted before and after the exposure period. The micro-hardness of the surface was measured using a diamond indenter of pyramid geometry with the top angle of $136^{\circ}$. The duration of the measurement was $45-$ $60 \mathrm{~s}$ for stainless steel specimens and $10-15 \mathrm{~s}$ for aluminum alloy specimens. The surface hardness was evaluated from the length of diagonals of the imprinted rectangular shape of the indenter according to the formula

$$
H V=0,189 \mathrm{~F} / \mathrm{d}^{2},
$$

where $d$ is an averege value of lenghts of diagonals and $F$ is the force load.

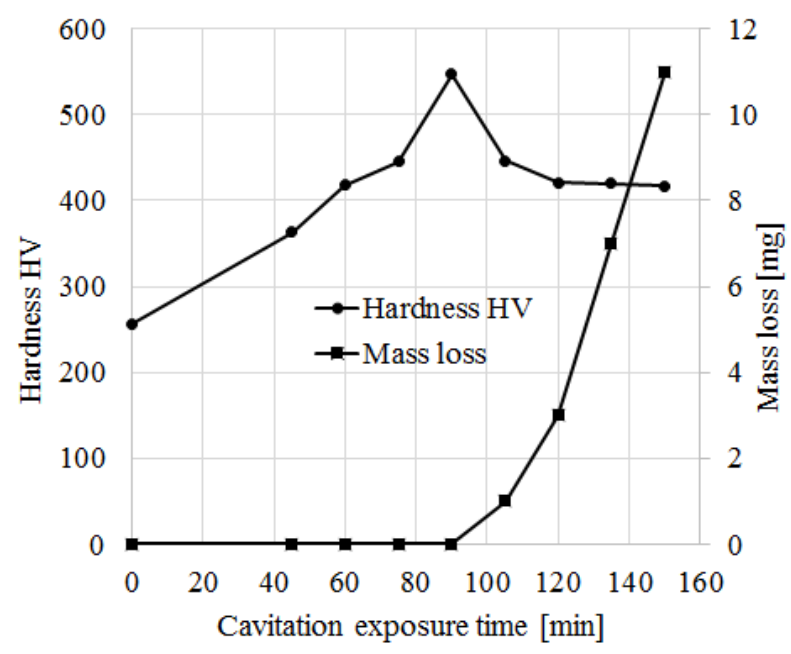

Fig. 5. Evaluation of the cavitation erosion for the stainless steel specimen.
The lenght of diagonals was measured by an optical microscope. The force load for the measurement was set to $0,2 \mathrm{~N}$ to ensure the diagonals visibility on the specimen after the cavitation exposure period. For each specimen the micro hardness was measured at 15 different points of the specimen surface.

\section{Results evaluation}

For each specimen the mass loss after the cavitation exposure period and the modification of the surface hardness were evaluated. Figure 5. shows the mass loss and the surface hardness change for the stainless steel specimen.

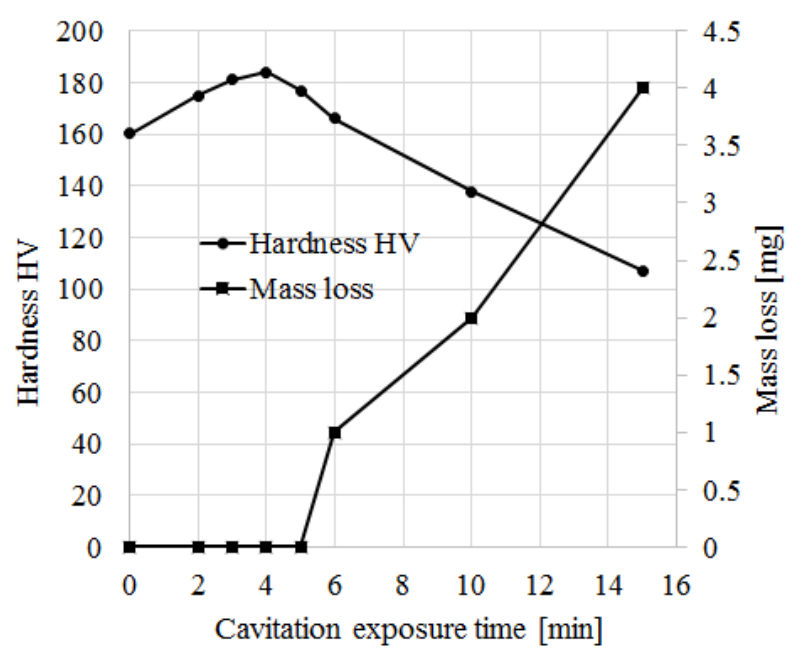

Fig. 6. Evaluation of the cavitation erosion for the aluminium alloy specimen.

The incubation period for the tested specimens was about 90 minutes. In this interval no mass loss was detected. The mass loss rate for this material is shown in Table 2. The mass loss rate increases after the incubation period and reaches the maximum after 135 minute of the exposure time and then is constant. The specimen hardness increases during the incubation period and reaches the maximum $\mathrm{HV} 547$ at the end of the incubation period. After this point the surface hardness decreases and then remains almost constant.

Figure 6. shows the mass loss and the surface hardness change for the aluminium alloy specimens. The incubation period for aluminium alloy specimens was about 5 minutes. After this time the mass loss rate increases. The surface hardness increases approximately till the end of the incubation period to value of HV 184 and then decreases.

It can be seen that the incubation period for the aluminium alloy is significantly shorter than the incubation period for the stainless steel. The mass loss rate at the beginning of the cavitation erosion process is slower for the stainless steel, which corresponds to the significantly better mechanical properties of this material. The increase in the surface hardness is more than two times higher for the stainless steel than for the aluminium alloy. 
Table 2. The mass loss rate evaluation for different periods of the cavitation exposure.

\begin{tabular}{|c|c|c|c|}
\hline \multicolumn{2}{|c|}{ Aluminum alloy } & \multicolumn{2}{c|}{ Stainless steel } \\
\hline $\begin{array}{c}\text { Cavitation } \\
\text { exposure } \\
\text { time }\end{array}$ & $\begin{array}{c}\text { Mass loss } \\
\text { rate }\end{array}$ & $\begin{array}{c}\text { Cavitation } \\
\text { exposure } \\
\text { time }\end{array}$ & $\begin{array}{c}\text { Mass } \\
\text { loss rate }\end{array}$ \\
\hline$[\mathrm{min}]$ & {$[\mathrm{mg} / \mathrm{h}]$} & {$[\mathrm{min}]$} & {$[\mathrm{mg} / \mathrm{h}]$} \\
\hline 2 & $\mathrm{x}$ & 45 & $\mathrm{x}$ \\
\hline 3 & $\mathrm{x}$ & 60 & $\mathrm{x}$ \\
\hline 4 & $\mathrm{x}$ & 75 & $\mathrm{x}$ \\
\hline 5 & $\mathrm{x}$ & 90 & $\mathrm{x}$ \\
\hline 6 & 60 & 105 & 4 \\
\hline 10 & 15 & 120 & 8 \\
\hline 15 & 24 & 135 & 16 \\
\hline $\mathrm{x}$ & $\mathrm{x}$ & 150 & 16 \\
\hline
\end{tabular}

It can be also seen that for the stainless steel specimens the surface hardness increases more than two times from its initial value, whilst the surface harness for the aluminium alloy specimens increases only about $14 \%$.

\section{Conclusion}

Presented article shows the first results of the investigation of the possible improvement of the surface hardness by the ultrasonic cavitation peening. The results shows the possibility of using the ultrasonic cavitation to improve the surface hardness of the tested material.

In the measurement the mass loss and the modification of the surface hardness were evaluated on different specimens exposed to the cavitation field for different time periods. This method however can introduce some errors connected to the specimen replacement and different structure of each specimen. On the other hand this measurement procedure improves the quality of the micro hardness measurement. It is also clear that the surface hardness is only one of many parameters, which can be influenced by the peening process.

The future work will be connected to the testing of other methods for the evaluation of the surface hardness and to the evaluation of the other material properties which can be influenced by the cavitation peening process.

\section{Acknowledgement}

This publication was written at the Technical University of Liberec as part of the project "Experimental and numerical investigation in applied fluid mechanics and energy devices" with the support of the Specific University Research Grant, as provided by the Ministry of Education, Youth and Sports of the Czech Republic in the year 2016, internal no. 21124.

\section{References}

1. Ch. E. Brennen, Cavitation and Bubble Dynamics, Oxford University Press (1995)

2. D. Odhiambo, H. Soyama, Int. J. Fatigue, 25 (2006)

3. Y. Gao, B. Wu, Z. Liu, Y. Zhou, N. Shen, H. Ding, J. Manuf. Sci. E-T ASME, 136 (2014)

4. H. Soyama, Y. Sekine, Int. J. Sustainable Eng., 3 (2010)

5. H. Soyama, D. O. Macodyio, S. Mall, Tribol. Lett., 17, 3 (2004)

6. Y. Gao, M. Yao, J. Li, Metall. Trans., 33, 6 (2002)

7. J. P. Franc, J. M. Michel, Fundamentals of cavitation, Kluwer academic publisher (2005)

8. Z. Li, J. Han, J. Lu, J. Zhou, J. Chen, Wear, 321 (2014) 